\title{
The genus Knightonia Carvalho and Drake (Miridae:Dicyphinae:Hyaliodini) ${ }^{1}$
}

\author{
J. Maldonado Capriles ${ }^{2}$
}

\begin{abstract}
Knightonia froeschneri n. sp. from Peru and Argentina is described. A key is provided to separate the three species in the genus.
\end{abstract}

\section{INTRODUCTION}

Carvalho and Drake described the genus Knightiella in $1943,{ }^{3}$ designating $K$. knighti from Ecuador as the type of the genus. In 1944 they proposed the new name Knightonia since it was discovered that Knightiella was preoccupied in the Mollusca. ${ }^{4}$ Carvalho in $1953^{5}$ described a second species, Knightonia peruana, and erroneously again assigned senior types and paratypes to Knightonia knighti (Carvalho and Drake), this time from specimens from Argentina. Dr. Richard C. Froeschner examined the type material and lent me specimens from Peru and the same locality in Argentina as that of the specimens in Carvalho's last paper. He pointed out to me differences between the original specimens of $K$. knighti and those from Argentina. Dr. Froeschner and I agree that the latter specimens represent a new species, described below.

The senior types are deposited in the collection of the National Museum of Natural History in Washington, D. C., and a paratype in my collection (JMC). Measurements are given in $\mathrm{mm}$.

\section{DESCRIPTIONS}

\section{KNIGHTONIA FROESCHNERI MALDONADO, NEW SPECIES}

Knightonia knighti (Carvalho and Drake, 1953), nec 1943: synonym in part-female allotype and some paratypes.

Male-vertex brownish, polished; collum slightly darker; eyes and

${ }^{1}$ Manuscript submitted to Editorial Board June 24, 1983.

${ }^{2}$ Department of Anatomy, Ponce School of Medicine, Ponce, PR, 00732, and Department of Plant Protection, College of Agricultural Sciences, University of Puerto Rico, Mayagüez, PR 00708 . The author is indebted to Dr. Richard C. Froeschner, National Museum of Natural History, Washington, D. C., for the loan of specimens and for designing the key used below.

${ }^{3}$ Carvalho, J. C. M. and C. J. Drake, A new genus and two new species of neotropical Dicyphinae (Hemiptera, Miridae), Rev. Brasil. Biol. 3(1):87-89, 1943.

${ }^{4}$ Knightonia, nom. nov. (Hemiptera, Miridae), Rev. Entomología, 15(1-2):239, 1944.

${ }^{5}$ Carvalho, J. C. M., Neotropical Miridae, LXIII: Genus Knightonia Carvalho \& Drake with description of a new species (Hemiptera), Acad. Brasil. Cienc., 25(2):171-173, 1953. 
second antennal segment black; beak and first antennal segment yellow stramineous. Pronotum variable in coloration; calli brown; collar and posterior lobe light yellowish brown, posterior lobe with a blotch of dark brown on each side of median line, posterior margin narrowly greenish or yellowish white (Plate I, fig. 6); mesopleura dark brown, metapleura brownish medially, blackish laterally; scutellum on cephalic slope mostly brownish, laterally and behind blackish (mostly blackish in some para-
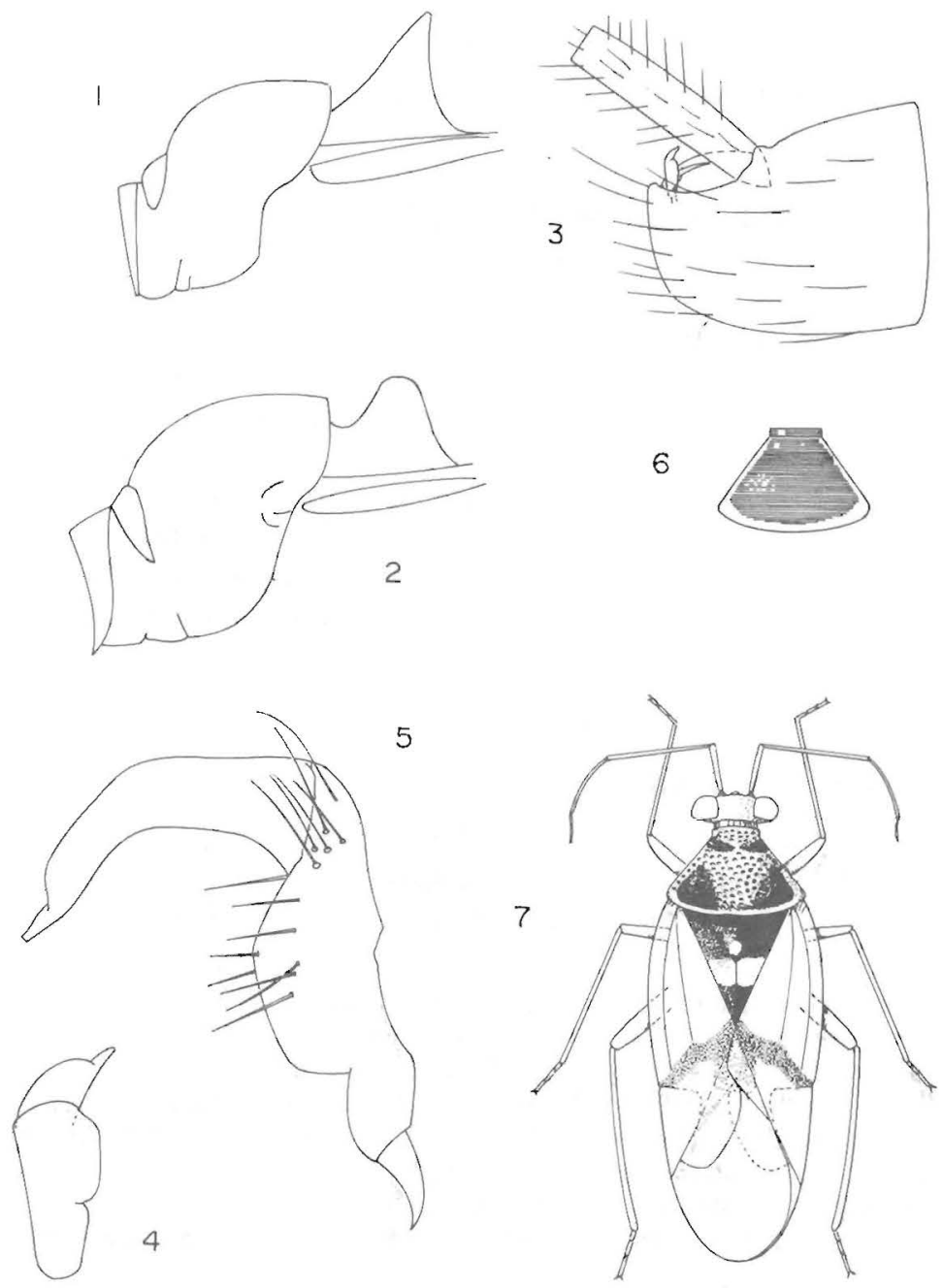

Plate I.- Knightonia knighti. 1) scutellum, lateral.

Knightonia froeschneri, male, 2) scutellum, lateral; 3) genital capsule, lateral; 4) right clasper, dorsal; 5) left clasper, dorsal; 6) variation in coloration, pronotum; 7) habitus. 
types). Thoracic sterna, legs, osteolar peritreme, and abdomen yellowish. Hemelytra hyaline, with very slight yellowish tinge; clavus mostly blackish, with the middle third yellowish translucent; an arcuate brownish band from apex of clavus to apex of embolium; anal area of hemelytra brownish.

Head: width across eyes 0.81 , interocular space 0.25 , length 0.2 , anterior margin slightly convex, posterior margin finely carinate; short polished collum. Antenna: I, 0.45; II, 1.2; III and IV missing; I glabrous, II finely short decumbent pilose. Beak reaching middle coxae. Pronotum: collar and posterior lobe pitted; calli polished, smooth; posterior margin straight above scutellum, slightly curved to humeral angles; length 0.95 , width at humeral angles 1.2. Mesoscutum and scutellum smoooth; scutellum with apical prominence, apex bluntly rounded (fig. 2) and at or slightly surpassing level of pronotum. Width across hemelytra 1.75; embolium wide, greatest width slightly shorter than width of eye (0.2:0.3), concave; cuneus: length 0.9 , width 0.5 . Genital segments as in figures 3 to 5 . Overall length $4.3-4.4 \mathrm{~mm}$.

Female-Head dark brown; pronotum black, posterior margin narrowly greenish white. Meso- and metapleura blackish. Mesoscutum black, prominence of scutellum anteriorly dark brown, remaining parts black. Other parts and pattern of hemelytra as in male, the pattern in black.

Head: width across eyes 0.77 , interocular space 0.3 , length 0.3 ; anterior margin and posterior carina as in male. Antenna: I, 0.5; II, 1.14; III, 0.49; IV, 0.51; segments II to IV finely short decumbent pilose. Beak reaching middle coxae. Pronotum as in male; length 0.95 , width 1.25 . Width across hemelytra 1.77; cuneus: width 0.46 , length 0.88 . Overall length $4.5 \mathrm{~mm}$.

Holotype - male, PERU, Santa Isabel, Dept.Cuzco, Valley of Cosnipata River, Dec. 19, 1951, F. Woytowski collector, in the NMNH, Cat. No. 100697. Allotype-female, same collecting data, Nov. 26, 1951, in the NMNH. Paratypes: 2 males, ARGENTINA, Tucumán, Dec. 1949 (genitalia dissected by Carvalho and illustrated in his 1953 paper) and June 1948, P. Wygodzinsky collector; one male, same data as holotype, I.26.52, Woytowski collector, in JMC.

\section{DISCUSSION}

As mentioned above the coloration of the pronotum is quite variable. It can be as in the allotype (fig. 6) or as in the holotype. The blotches in the latter case can be small, medium, separated or connected. There is no correlation between sex and coloration; one male paratype has a black pronotum like that of the female allotype. On the other hand, the coloration of the clavus and the shape of the prominence of the scutellum are constant. Two specimens at hand, also from Tucumán, Argentina may represent an undescribed species even though they are colored almost exactly like the female allotype described above. 
Key to the species of Knightonia.

1. Clavus with a broad yellowish translucent band across middle third

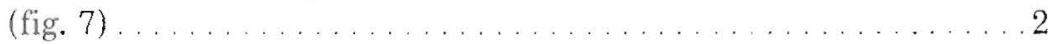

Clavus with apical two-thirds, except claval margin, pale translucent. Length $5.1 \mathrm{~mm}$..................... peruana Carvalho

2. Scutellar prominence elevated by about half its length above the level of pronotum, in lateral and posterior views its apex sharply acute. Antennal I with a prominent black stripe along its dorsolateral face. Length $4.2-4.8 \mathrm{~mm}$. . . . . . . . . knighti (Carvalho and Drake)

Scutellar not or very slightly elevated above level of pronotum, its apex narrowly, bluntly rounded. Antennal segment I yellow. Length $4.3-4.5 \mathrm{~mm}$ froeschneri new species

\section{RESUMEN}

Se describe Knightonia froeschneri, nov. sp., de ejemplares de Argentina y Perú y se señala que $K$. knighti es sinónima en parte con esta. Se ofrece una clave para separar las tres especies del género. 